\title{
Perspectives on Suicide and Depression in Children and Adolescents and Beyond
}

\author{
By Eric Hollander, MD
}

Depression is common among adolescents, is associated with a high risk of suicide, and is one of the leading causes of death among this population in the United States. Much is not fully understood and there is considerable controversy regarding many issues in child and adolescent suicide and depression. Do antidepressants cause an increase in the rates suicidal thoughts and behavior in this population? Are suicidal thoughts and behaviors associated with true suicidal attempts? Has a decrease in prescribing of antidepressants in the child/ adolescent population over the last few years resulted in an increase in completed suicides? A clearer understanding of adolescent depression and its relationship to suicide may help to clarify some of these isssues.

I would like to thank Kelly Posner, PhD, the guest editor of this issue. She is the director of the Suicide Classification Center at Columbia University. She has contributed important work for the Food and Drug Administration to develop a system to classify suicidal symptoms in pediatric antidepressant pharmacotherapy trials. For this issue, Posner has collected articles that summarize existing data and treatments and looks to future of treatment for suicide and depression in young people.

Anat Brunstein Klomek, PhD, and Barbara Stanley, PhD, describe cognitive-behavioral therapy and interpersonal psychotherapy to target suicidal behavior in depressed adolescents. Taryn L. Mayes, MS, and colleagues report that contrary to expectations, fluoxetine-placebo difference was greater in children compared to adolescents.
Suicide remains a leading cause of death among youth, and suicide ideation and behavior are relatively common in normal and clinical populations. Clinicians working with young people are often required to assess for the presence of suicidal ideation, suicidal behavior, and other risk factors, and to determine the level of risk. Kelly Posner, PhD, and colleagues provide the clinician with a summary of risk factors for youth suicide as well as providing standardized terminology to enhance the clinician's assessment of suicidal ideation and behavior.

Compulsive buying disorder is characterized by excessive or poorly controlled preoccupations, urges, or behaviors regarding shopping and spending that lead to subjective distress or impaired functioning. Donald W. Black, MD, describes how compulsive buying disorder has a lifetime prevalence of $5.8 \%$, and that in clinical but not epidemiologic settings, most persons with compulsive buying disorder are women. The disorder occurs mainly in developed countries and tends to run in families with a history of mood disorders and substance misuse. There is no standard treatment for compulsive buying disorder, but group cognitive-behavioral models seem promising, and psychopharmacologic treatments are being actively studied. Other treatment options include simplicity circles, 12step programs, financial counseling, bibliotherapy, marital therapy, and financial counseling.

Daniel D. Christensen, MD, reviews the amyloid hypothesis - the leading mechanistic theory of Alzheimer's disease. An imbalance in production or clearance of amyloid $\beta(A \beta)$ results in accumulation of $A \beta$ and triggers a cascade

Dr. Hollander is the editor of this journal, Esther and Joseph Klingenstein Professor and Chairman of Psychiatry at the Mount Sinai School of Medicine, and director of the Seaver and New York Autism Center of Excellence in New York City. 
of events leading to neurodegeneration and dementia. Different classes of potentially disease-modifying treatments that interrupt early pathological events (ie, decreasing production or aggregation of $A \beta$ or increasing its clearance) and potentially prevent downstream events are in phase II or III clinical studies: immunotherapies; secretase inhibitors; selective $A \beta_{42}$-lowering agents; statins; anti-A $\beta$ aggregation agents; peroxisome proliferator-activated receptorgamma agonists; and others.

David E. Kemp, MD, and colleagues show how bipolar disorder is frequently associated with obsessional symptoms. However, no reports have identified a pattern of obsessionality that is associated with a specific mood stabilizer treatment. Five patients with bipolar II disorder were identified who developed a form of obsessionality characterized by intrusive, recurrent phrases after taking lamotrigine. A possible mechanism for the development of the intrusive phrases involves the influence of lamotrigine on glutamatergic regulation in a bipolar II disorder population vulnerable to the expression of obsessionality.

Also this month, CNS Spectrums is very pleased to launch a new regularly occurring column by Stephen M. Stahl, MD, PhD, called "Trends in Psychopharmacology." I think that you will find it of great interest, and a nice complement to our current selection of columns. CNS

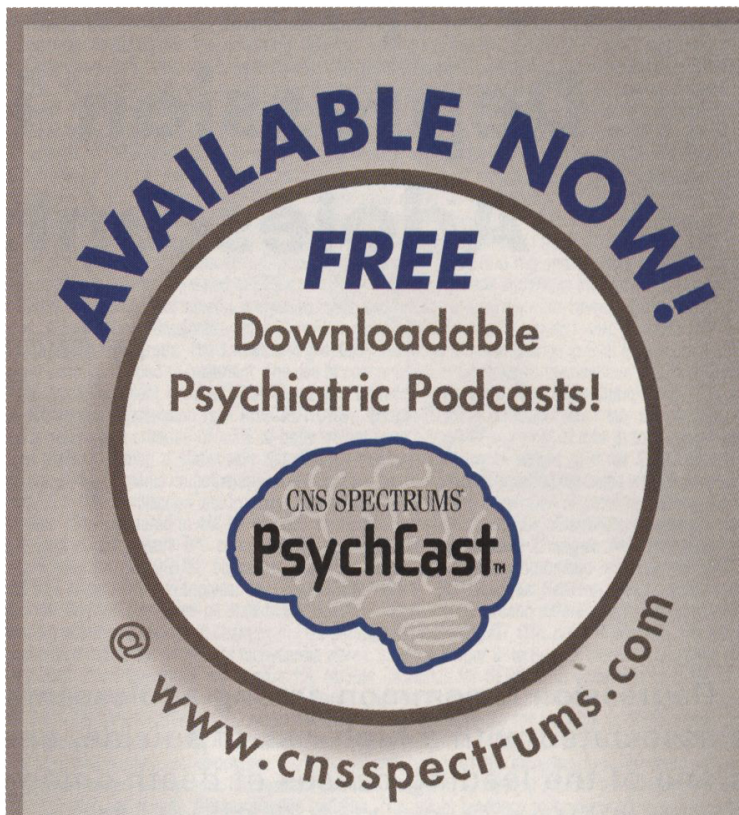

PsychCast ${ }^{T M}$ is designed to enable physicians to simply and easily listen to a compilation of insightful, 20-35 minute interviews with internationally recognized researchers and clinicians in the fields of psychiatry and neuropsychiatry. Additional 2007 PsychCast ${ }^{T M}$ programming will include peerreviewed expert panel dialogues, casebased psychopharmacology lessons, and other educational programs designed to provide our 115,000+ monthly readers with an additional level of personalization in the era of multi-channel learning.

Richard H. Weisler, MD, on the topic of "Treatment of Attention-Deficit/ Hyperactivity Disorder"

J. Craig Nelson, MD, on the topic of "Treating Late-Life Depression"

Kimberly A. Yonkers, MD, on the topic of "Treating Depression in Pregnancy"

Please E-mail us at info@mblcommunications.com to recommend clinical topics you would like to learn about via PsychCast ${ }^{\text {MM }}$ 
BRIEF SUMMARY: Consult the full prescribing information for complete product information.

MDICATIOH ANO USAGE

CII Ax Only

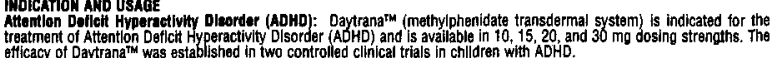

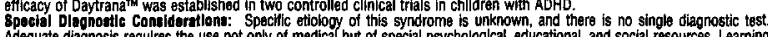

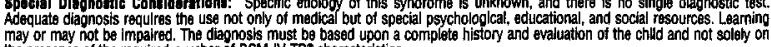
the presence of the required number of DSM-V $V$-TR $R^{\circ}$ characteristics.

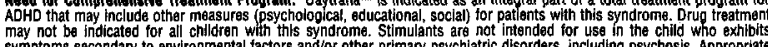

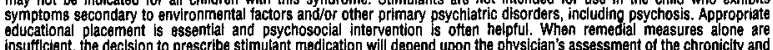

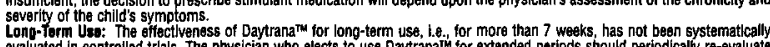

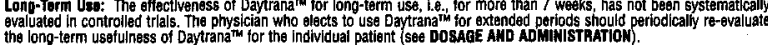
CONTRAANDICATrOONB

Agltenlon: Daytranam is contraindicatsod in patients whth marked anxiety, tension, and agtation, sinces the drug may aggravare these

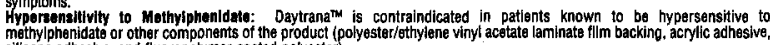
sillcone adhesive, and fluoropolymer-cosited polyester

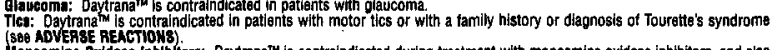

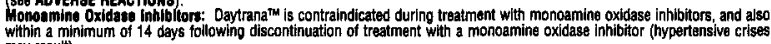
may resultin.
WARHings

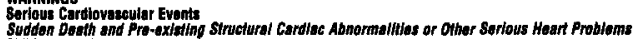

Shildren and Adglescents

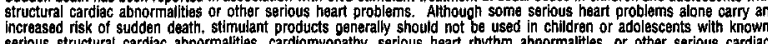

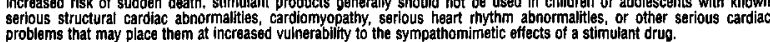
Addults
Sudden coaths, stroke, and myocardial Infarction have boen roported in adults taking stimulant drugs at usual doses for ADHD.
Althoug the

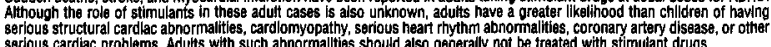
serilous cardiac problems. Adutts with such abmormalties should also generally not be traated with stirnulant drugs.

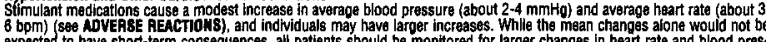

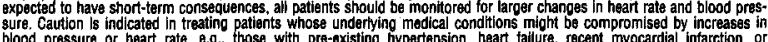

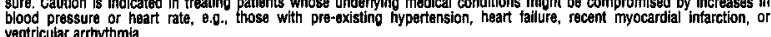

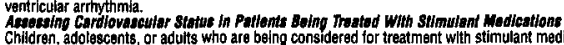

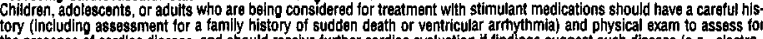

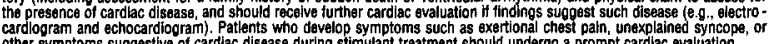

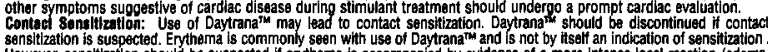

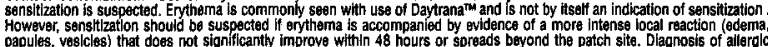

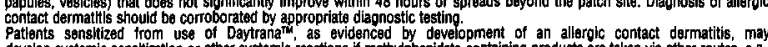

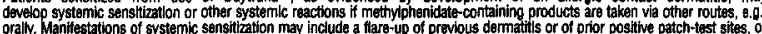

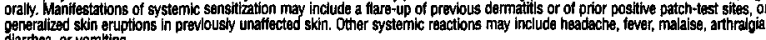

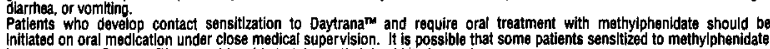

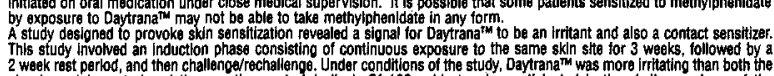

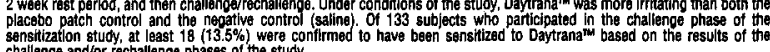

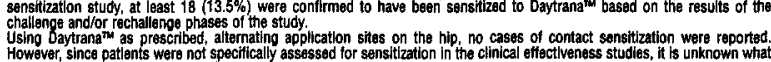

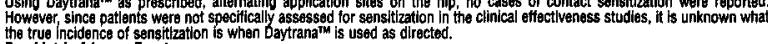
Poyethimels Raventa Evente

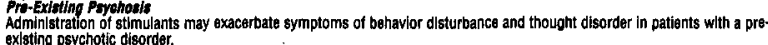
exlating psychotic disorder.

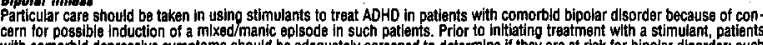

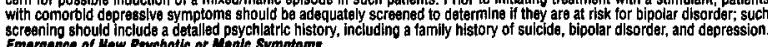

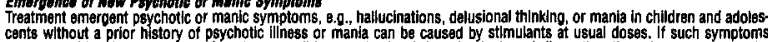

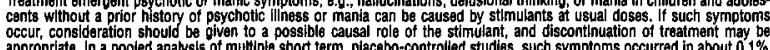

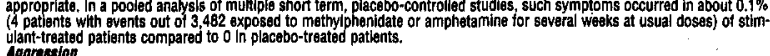

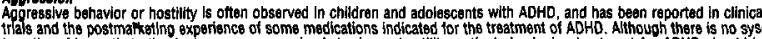
tematlc evidence that stimulants cause agoressive behavior or hostility, patients beginning treatiment for ADHO should bo

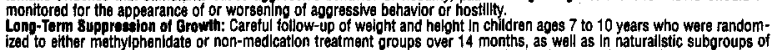

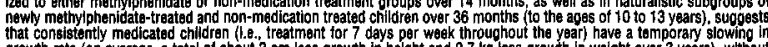

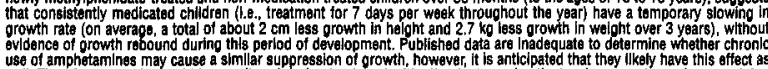

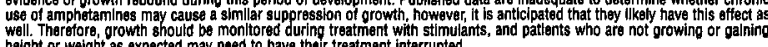

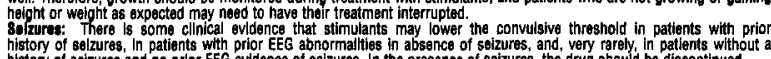

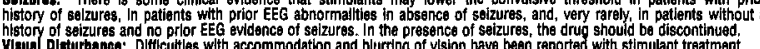

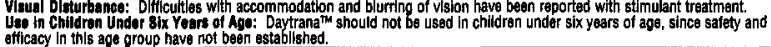

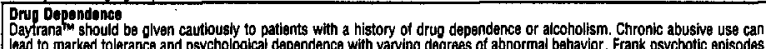

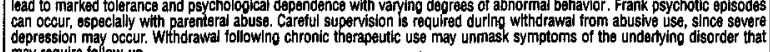
may require tologen

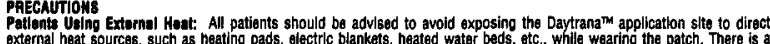

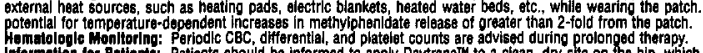

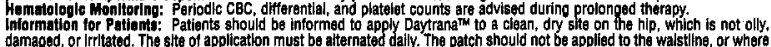

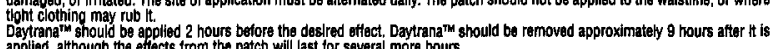
appliad, although the efiects from the patch will last for several more hours. montitor applicatton and removel time, and methoot of disposal,

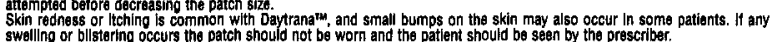

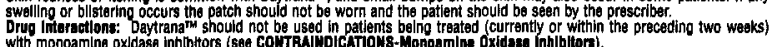

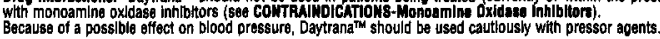

Methylphenidate may decrease the effiectlveness of drugs used to treat hyportengion.
Human pharmacologic studes

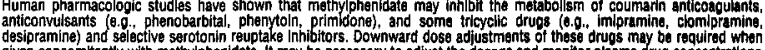

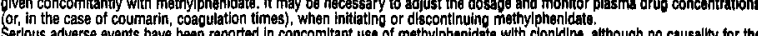

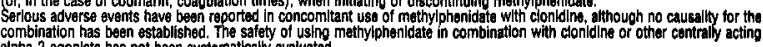

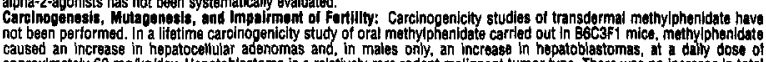

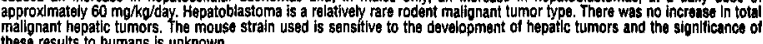

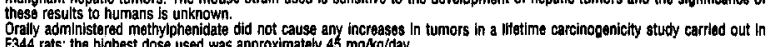

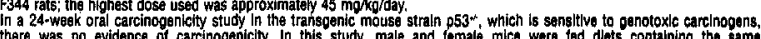

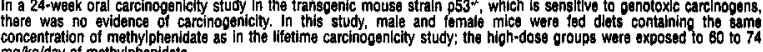

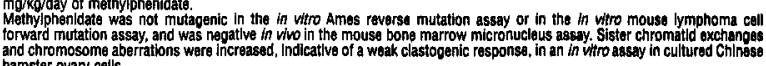

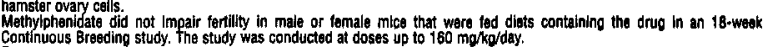
up to 100 mokd day

Prepinaney Categery C: Animal reproduction studies with transsiermal metthylphanidate have not been pertiorned. In a studty in

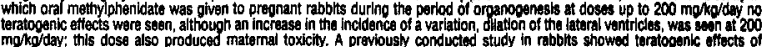

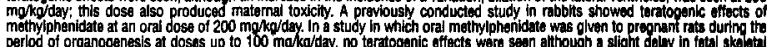

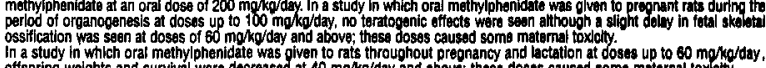

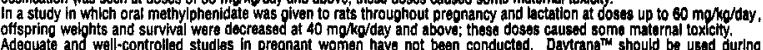

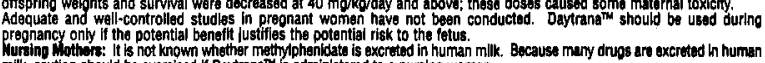

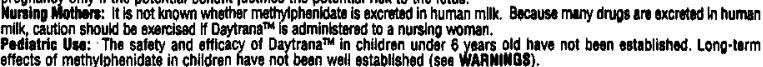

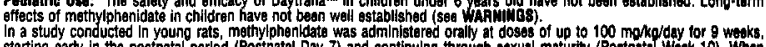

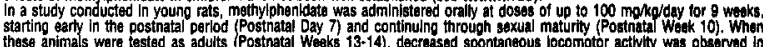

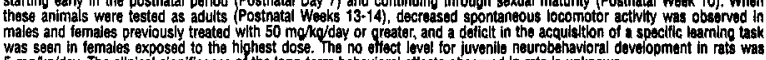

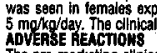

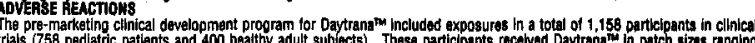

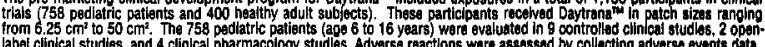

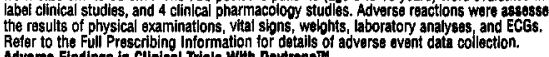

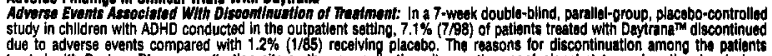

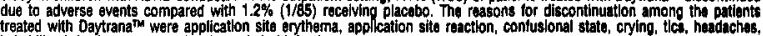

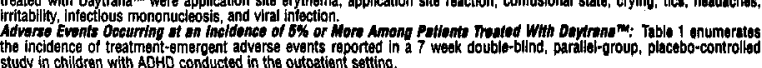

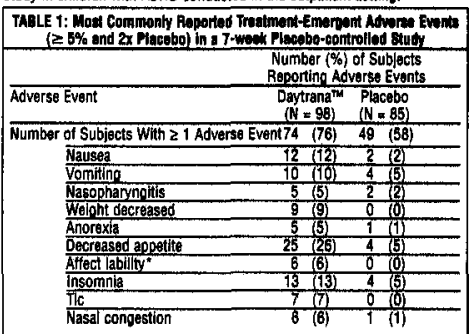

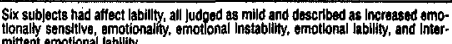
The majority of subjects in the poivotal phase

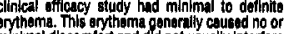
minimal discomfor and did not usually lintritor

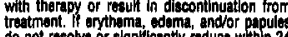
so not resolvo or signilicantly raducs within 2 hours after pasten removal, further ovaluation indcation of contact sonstitizition. Howewor, accompanied by edoma, papules, visidiess, or Othar evidences of more intensa iocal reactions.

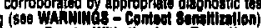

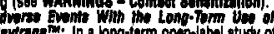

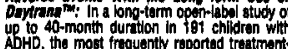

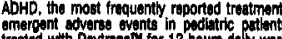

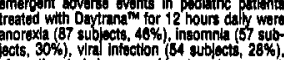

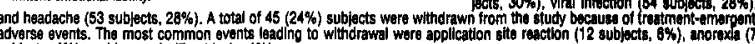
subiects, 4\%), and insomnia $(7$ sublects, 4\%).

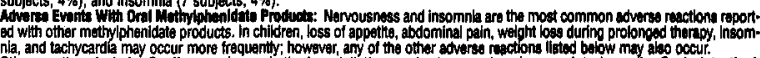

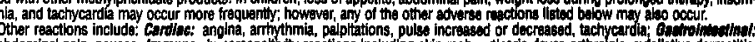

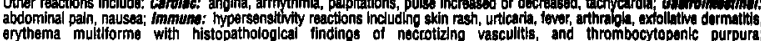

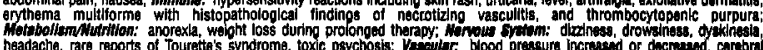

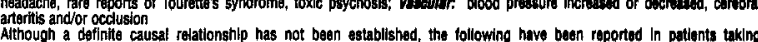

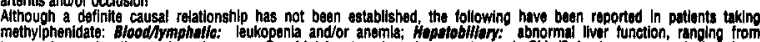

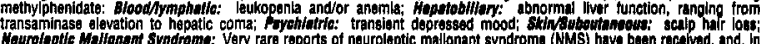

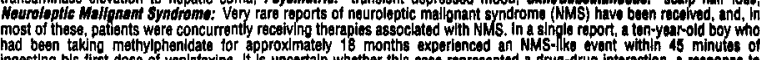

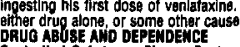

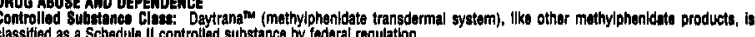

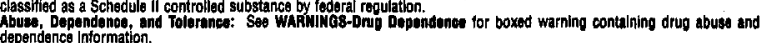

8lans and Symptomit: Signs and symptoms of acute methylphonidate overdocage, resulting principally from overatimulation

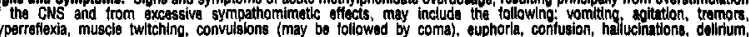

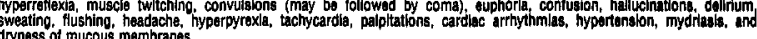

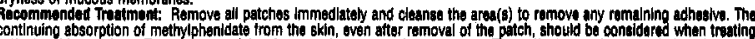

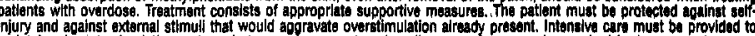

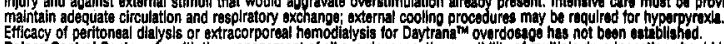

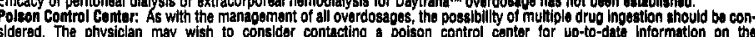

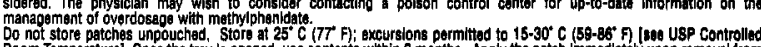

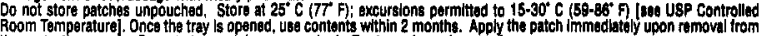
the protective pouch. Do not store patches unpouched. For trondiomul use only.

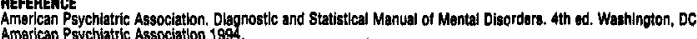

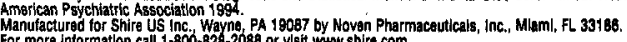

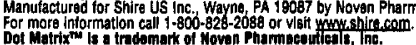

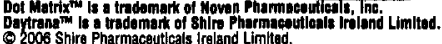

$\begin{array}{lll}\text { Pux Only } \\ 102086-1 & 5521027002 & \text { Rev. 08:06 }\end{array}$ 


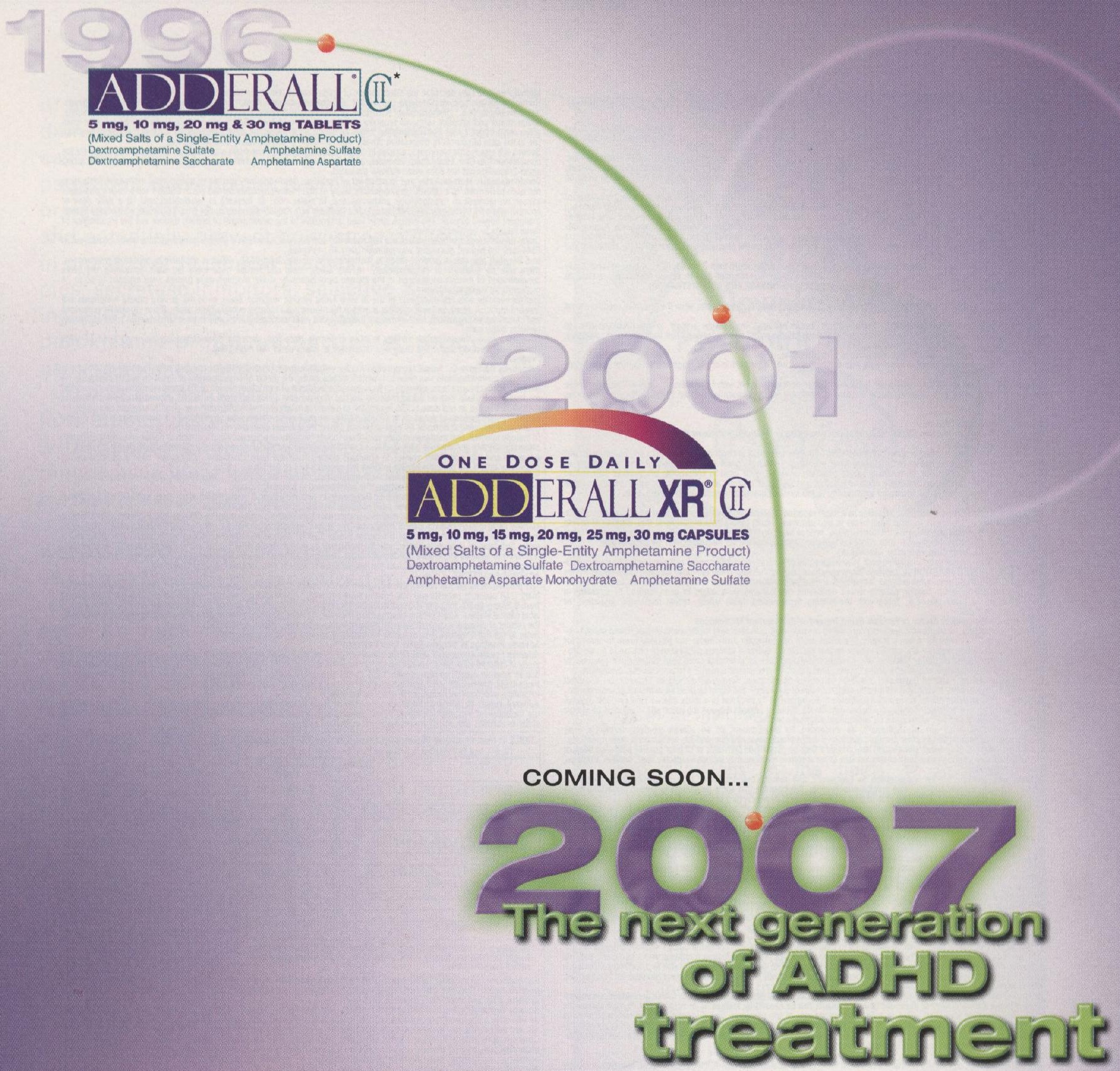

\section{Important Safety Information}

Adderall XR should not be used in patients with advanced arteriosclerosis; symptomatic cardiovascular disease; moderate to severe hypertension; hyperthyroidism; known hypersensitivity or idiosyncrasy to sympathomimetic amines; agitated states; glaucoma; a history of drug abuse; or during or within 14 days after treatment with monoamine oxidase inhibitors (MAOIs).

Sudden death has been reported in association with CNS stimulant treatment at usual doses in children and adolescents with structural cardiac abnormalities or other serious heart problems. Sudden deaths, stroke, and myocardial infarction have been reported in adults taking stimulant drugs at usual doses in ADHD. Physicians should take a careful patient history, including family history, and physical exam, to assess the presence of cardiac disease. Patients who report symptoms of cardiac disease such as exertional chest pain and unexplained syncope should be promptly evaluated. Use with caution in patients whose underlying medical condition might be affected by increases in blood pressure or heart rate.

New psychosis, mania, aggression, growth suppression, and visual disturbances have been associated with the use of stimulants. Use with caution in patients with a history of psychosis, seizures or EEG abnormalities, bipolar disorder or depression. Growth monitoring is advised during prolonged treatment. Amphetamines have a high potential for abuse. Administration of amphetamines for prolonged periods of time may lead to drug dependence. Particular attention should be paid to the possibility of subjects obtaining amphetamines for nontherapeutic uses or distribution to others and the drugs should be prescribed or dispensed sparingly. Misuse of amphetamine may cause sudden death and serious cardiovascular adverse events.

The most common adverse events in clinical studies of Adderall XR included: pediatric-loss of appetite, insomnia, abdominal pain, and emotional lability; adolescent-loss of appetite, insomnia, abdominal pain, and weight loss; adult-dry mouth, loss of appetite, insomnia, headache, and weight loss.

\section{Please see Brief Summary of Prescribing Information, including Boxed Warning, on adjacent page.}

*Adderall ${ }^{\odot}$ is a registered trademark of Shire LLC, under license to Duramed Pharmaceuticals, Inc.

Shire US Inc. 